\title{
Modeling Procedure of Coastal Protection Shaped Blocks with High Wave Suppressing and Interlocking Capacity
}

\author{
Irina Iordanishvili ${ }^{1}$, Inga Iremashvili ${ }^{2}$, Adam $\mathrm{Ujma}^{3^{*}}$, Vladimer Shurgaya ${ }^{4}$, Nodar Kandelaki ${ }^{5}$, \\ and Konstantin Iordanishvili ${ }^{6}$ \\ 1,2,4,5,6 Tsotne Mirtskhulava Water Management Institute of Georgian Technical University. 60-b, I. \\ Chavchavadze Ave., 0179, Tbilisi, Georgia \\ ${ }^{3}$ Czestochowa University of Technology, Faculty of Civil Engineering, ul. Akademicka 3, 42-200 \\ Czestochowa, Poland
}

\begin{abstract}
A groyne is a shore protection structure built perpendicular to the shoreline of the coast (or river), over the beach and into the shoreface (the area between the nearshore region and the inner continental shelf), to reduce longshore drift and trap sediments. A groyne field or system is a series of groynes acting together to protect a beach. Concret is often used as construction material.

On the basis of analysis of wave suppression efficiency and stability on the slope of more than one hundred existing shaped massives the new type of coast protecting reinforced concrete blocks - so called "Hexablock" ("Hexablock" was called because of its 6 facets) characterized with higher wave suppression properties, interlocking capacity, stability on the slope and longer life time is proposed.
\end{abstract}

\section{Introduction}

At the last years we are observing change in global mean sea level. This causes an increase in the erosion processes of the coasts.

Detached concrete blocks aim to protect a coast or activities along the coastline (e.g. ports, ship wharf) from wave action. In general terms, a detached breakwater is a coastparallel structure located inside or close to the surf-zone. Several types of breakwaters exist, from which detached breakwaters are the most common type. This article provides a general introduction of detached breakwaters and describes emerged breakwaters, submerged or low-crested breakwaters, floating breakwaters and other special type breakwaters. Different aspects of breakwaters as coastal protection are discussed, as well as their impacts on shoreline evolution.

Consideration of many factors stipulating development of the process is so difficult that the problem of modeling the real wave streams and their interaction with the coast protecting structures is not fully studied yet. According to the world practice of reservoirs bank protection methods the most efficient one is with shaped concrete blocks. 


\section{Shore protection against of sea erosion}

Over the period from January 1993 to May 2017, seas level has risen with a rate of about $3-4 \mathrm{~mm}$ per year, which translated to a global increase in mean sea level of about $8 \mathrm{~cm}$. [1] (Fig. 1). This process is the result of global warming. The level sea in the Baltic Sea has risen average $10.6 \mathrm{~cm}$, in the last 100 years. [2] An increase in the erosion processes of the sea coast is observed. [2, 3]

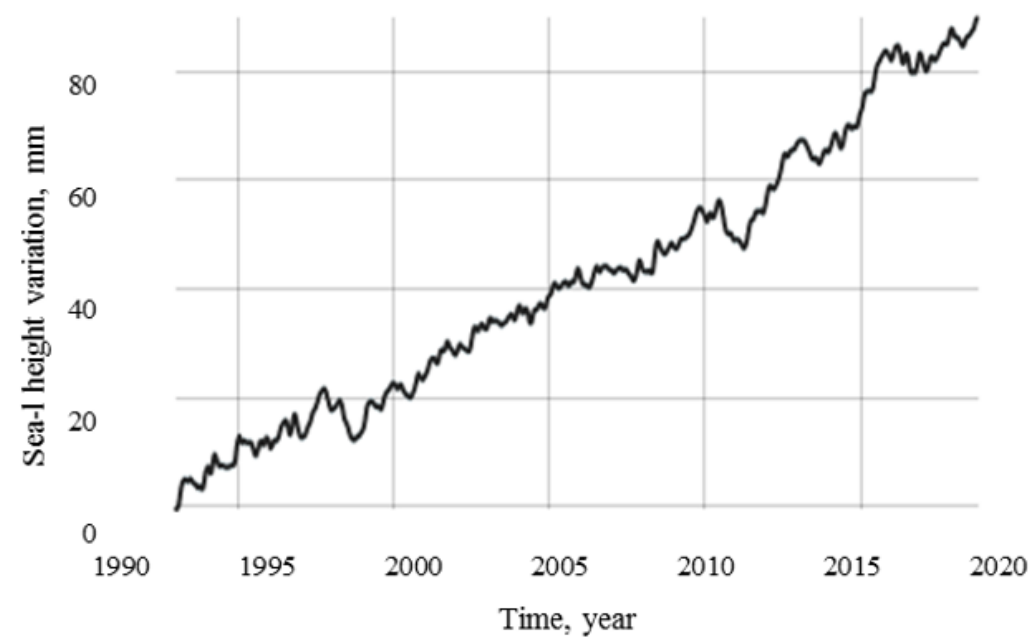

Fig. 1. Global sea-level rise (mm) since 1993 [1]

In the Baltics and Black Sea coastal zones, sea level has risen, with most areas showing trends of between $3-4 \mathrm{~mm}$ per year. [4] (Fig. 2)
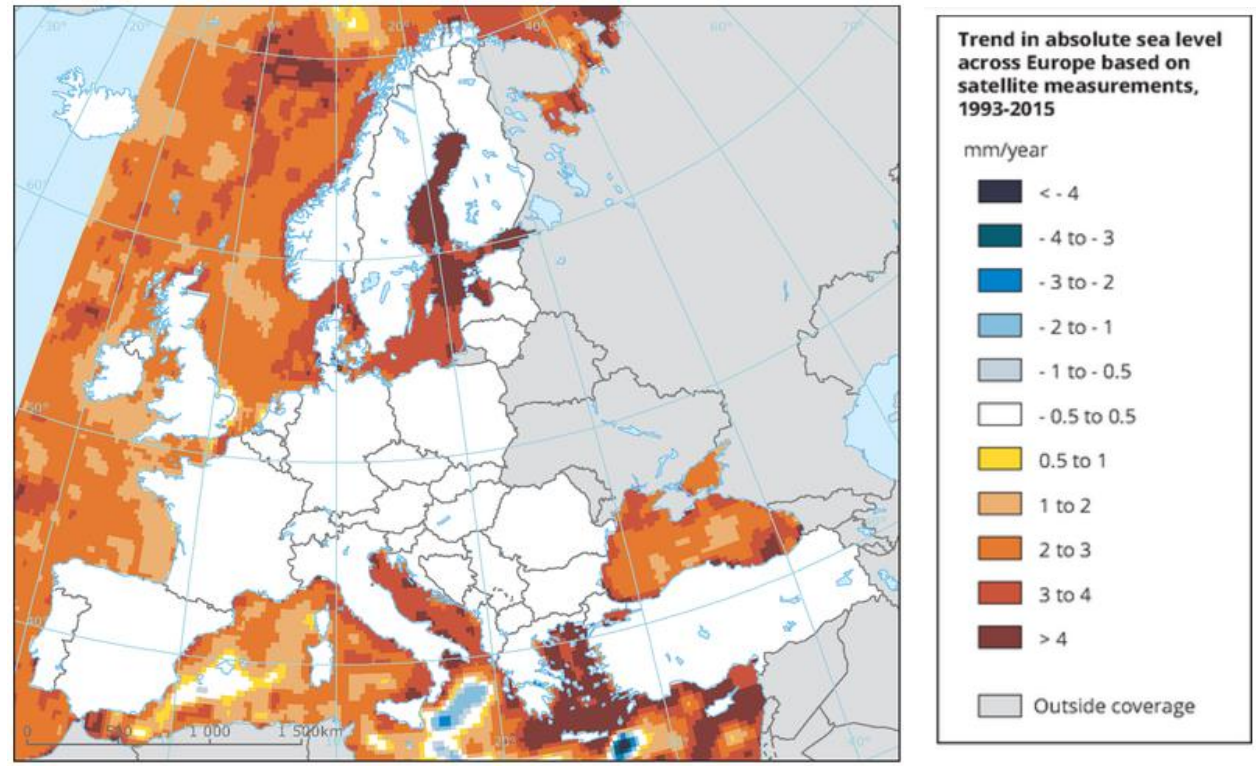

Fig. 2. Horizontal spatial distribution of mean sea level trend in European Seas (January 1993- December 2015) [4] 
These phenomena require intensification of activities that may reduce the erosion processes of the coastlines. One of such activities is the improvement of the groyne structure, which is designed to weaken the action of sea waves on the shore.

According to the analysis of more than one hundred relevant research works it has been determined that among the used shaped blocks the most popular are shaped blocks, (Fig. 3). [5-8]

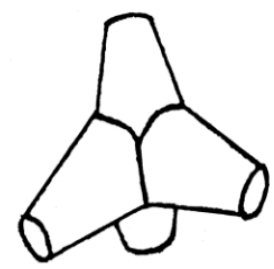

a) Tetrapod

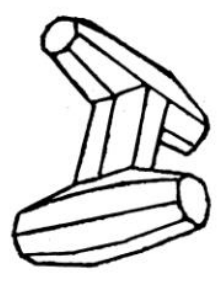

b) Dolos

Fig. 3. The most popular types of shaped blocks

In Georgia shore protection concrete blocks (tetrapods) is used only embankment of river Liakhvi to protect the main road, on the coastal zone of Black Sea, North - on the coastal of Anaklia port under construction and South - to Sarphi border. In Poland, tetrablocs are used, among other things, for securing the sea coasts of the cliffs, entering ports and reinforcing breakwaters (Fig. 4).

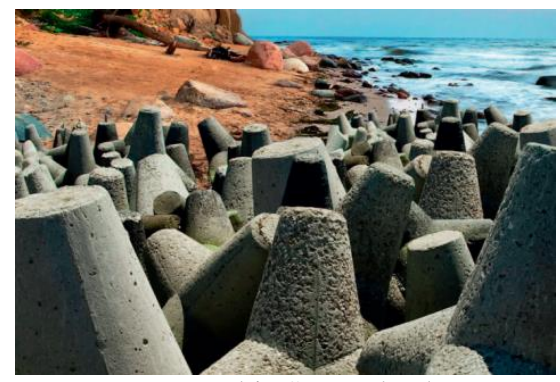

Baltic Sea, Poland

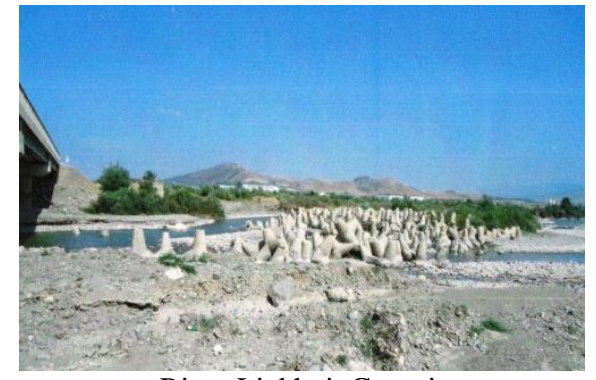

River Liakhvi, Georgia

Fig. 4. Offshore braekwater tetrapod blocks [9]

With a view to rise wave suppressing capacity of shaped blocks, their interlocking properties, stability at the shore line and the longer service lifetime the new type of shaped block the "Hexablock" in particular is proposed, (Fig .5) [10,11].

Today, many scientists are working on creating similar massive coastal defensive figures [12-15], but we will present a characteristic of our hexablocks, which is different from other shaped blocks.

\section{Calculation method of "Hexablock" stability}

The "Hexablock" weight that will ensure its limit equilibrium at the slope is determined by the approbated universal dependence. With a view to rise wave suppressing capacity of shaped blocks, their interlocking properties, stability at the shore line and the longer service lifetime the new type of shaped block the "Hexablock" in particular is proposed, (Fig. 5) $[8]$. 


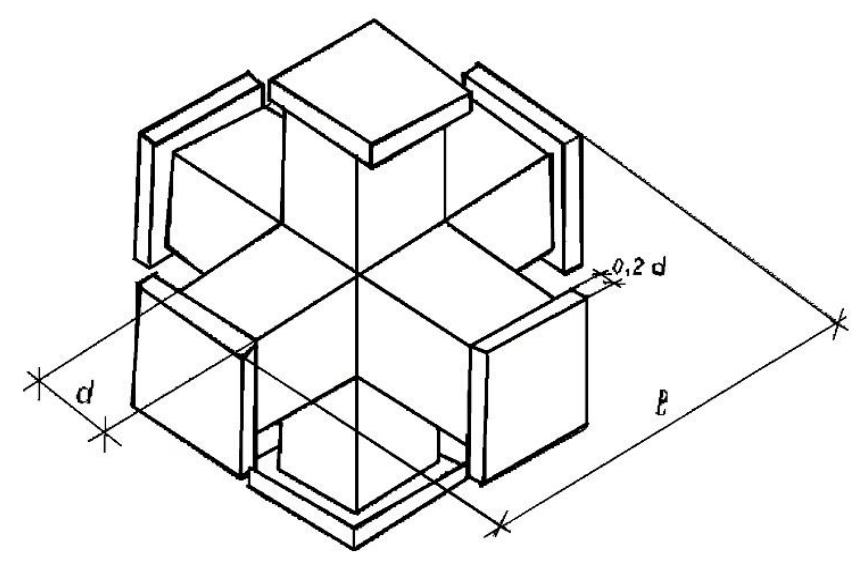

Fig. 5. The diagram of new type shaped massif - "Hexablock"

$$
\mathrm{M}=\frac{0,0165 \rho_{b} \mathrm{~h}_{1 \%}^{3}}{\left(\rho_{b}-1,02\right)^{3} \operatorname{ctg} \alpha} \sqrt{\frac{\lambda}{\mathrm{h}_{1 \%}}}
$$

where:

$\rho_{b}$ is the density of block material $\left(\mathrm{t} / \mathrm{m}^{3}\right), h_{1 \%}, \lambda_{1 \%}$ are the height and the length of $1 \%$ provision wave $(\mathrm{m}) ; \alpha$ - is the bank slope angle; $\rho=1.02$ is the density of the Black Sea water $\left(\mathrm{t} / \mathrm{m}^{3}\right)$.

If to assume for a first approximation that the height of natural scale "Hexablock"

$$
l_{\text {nat }} \approx \frac{h_{1 \%}}{3}
$$

where:

$h_{1 \%}$ is the height of $1 \%$ provision wave at the coast line, when

$$
\rho_{b}=2.4\left(\mathrm{t} / \mathrm{m}^{3}\right), \frac{\lambda}{h}=10, \operatorname{ctg} \alpha=3\left(\alpha=18^{0}\right),
$$

then the true weight $\left(P_{n a t}\right)$ of "Hexablock", the weight securing its stability on the slope $\left(M_{n a t}\right)$ and the model values $\left(h_{m o d}, P_{m o d}, M_{m o d}\right)$ will be summarized in Tables 1,2 and 3.

Table 1. The values of "Hexablock" actual (natural scale) and model design characteristics (for small chute $10.0 \times 0.3 \times 0.7 \mathrm{~m} ; a_{L l}=30$ )

\begin{tabular}{|l|c|c|c|c|c|c|c|}
\hline$H_{\text {nat }, \mathrm{m}} / h_{\text {mod, } \mathrm{m}}$ & $5.00 / 0.16$ & $5.70 / 0.19$ & $6.90 / 0.23$ & $7.50 / 0.25$ & $8.10 / 0.27$ & $8.40 / 0.28$ & $9.00 / 0.30$ \\
\hline$P_{\text {nat }, /} / P_{\text {mod }, \mathrm{kg}}$ & $1.70 / 0.06$ & $2.10 / 0.08$ & $4.50 / 0.17$ & $5.50 / 0.21$ & $7.10 / 0.26$ & $7.80 / 0.29$ & $8.00 / 0.30$ \\
\hline $\mathrm{M}_{\text {nat }, /} / \mathrm{M}_{\text {mod }, \mathrm{gg}}$ & $1.80 / 0.07$ & $2.20 / 0.08$ & $4.60 / 0.17$ & $5.90 / 0.22$ & $7.40 / 0.27$ & $8.00 / 0.30$ & $8.30 / 0.31$ \\
\hline$D_{\text {nat }, \mathrm{m}} / d_{\text {mod }, \mathrm{m}}$ & $0.40 / 0.010$ & $0.45 / 0.015$ & $0.55 / 0.018$ & $0.60 / 0.02$ & $0.65 / 0.022$ & $0.68 / 0.023$ & $0.73 / 0.024$ \\
\hline$S_{\text {nat, } \mathrm{m}} / S_{\text {mod }, \mathrm{m}}$ & $0.52 / 0.017$ & $0.63 / 0.021$ & $0.75 / 0.025$ & $0.83 / 0.028$ & $0.90 / 0.031$ & $0.95 / 0.032$ & $1.0 / 0.033$ \\
\hline$L_{\text {nat, }, \mathrm{m}} / l_{\text {mod }, \mathrm{m}}$ & $1.69 / 0.05$ & $1.90 / 0.06$ & $2.30 / 0.075$ & $2.50 / 0.08$ & $2.70 / 0.09$ & $2.80 / 0.09$ & $3.00 / 0.10$ \\
\hline
\end{tabular}


The said values were received by the hydro-technical laboratory of Water Management Institute of Georgian Technical University at the following installations: the large hydrowave chute $50.0 \mathrm{~m}$ long, $0.75 \mathrm{~m}$ wide, $1.5 \mathrm{~m}$ deep; the small hydro-wave chute with dimensions $10.0 \times 0.3 \times 0.7 \mathrm{~m}$; the small wave basin $7.0 \times 7.5 \times 1.1 \mathrm{~m}$ and large wave basin $30.0 \times 40.0 \times 2.0 \mathrm{~m}$.

Table 2. The values of "Hexablock" actual (natural scale) and model design characteristics (for large chute $50,0 \times 0,75 \times 1,5 \mathrm{~m} ; a_{L 2}=13$ )

\begin{tabular}{|l|c|c|c|c|c|c|c|}
\hline$H_{\text {nat, }, \mathrm{m}} / h_{\text {mod, } \mathrm{m}}$ & $5.00 / 0.39$ & $5.70 / 0.44$ & $6.90 / 0.53$ & $7.50 / 0.58$ & $8.10 / 0.62$ & $8.40 / 0.64$ & $9.00 / 0.70$ \\
\hline$P_{\text {nat }, t} / P_{\text {mod }, \mathrm{kg}}$ & $1.70 / 0.77$ & $2.10 / 0.96$ & $4.50 / 2.00$ & $5.50 / 2.50$ & $7.10 / 3.20$ & $7.80 / 3.50$ & $8.00 / 3.64$ \\
\hline $\mathrm{M}_{\text {nat }, /} / \mathrm{M}_{\text {mod }, \mathrm{kg}}$ & $1.80 / 0.80$ & $2.20 / 1.00$ & $4.60 / 2.10$ & $5.90 / 2.70$ & $7.40 / 3.40$ & $8.00 / 3.64$ & $8.30 / 3.80$ \\
\hline$D_{\text {nat, } \mathrm{m} /} / d_{\text {mod }, \mathrm{m}}$ & $0.40 / 0.030$ & $0.45 / 0.031$ & $0.55 / 0.042$ & $0.60 / 0.046$ & $0.65 / 0.050$ & $0.68 / 0.052$ & $0.73 / 0.056$ \\
\hline$S_{\text {nat }, \mathrm{m} /} / S_{\text {mod }, \mathrm{m}}$ & $0.52 / 0.040$ & $0.63 / 0.050$ & $0.75 / 0.060$ & $0.83 / 0.070$ & $0.90 / 0.070$ & $0.95 / 0.073$ & $1.0 / 0.077$ \\
\hline$L_{\text {nat }, \mathrm{m}} / l_{\text {mod }, \mathrm{m}}$ & $1.69 / 0.13$ & $1.90 / 0.15$ & $2.30 / 0.18$ & $2.50 / 0.19$ & $2.70 / 0.21$ & $2.80 / 0.22$ & $3.00 / 0.23$ \\
\hline
\end{tabular}

Table 3. Values of "Hexablock" actual ( $\left.\mathrm{a}_{\mathrm{L} 1} \mathrm{scale}\right)$ and model design characteristics (for spatial basin $7,0 \times 7,5 \times 1,1 \mathrm{~m} ; a_{L 3}=17$ )

\begin{tabular}{|c|c|c|c|c|c|c|c|}
\hline$H_{\text {nat,m }} / h_{\text {mod,m }}$ & $5.00 / 0.29$ & $5.70 / 0.34$ & $6.90 / 0.41$ & $7.50 / 0.44$ & $810 / 0.48$ & $8.40 / 0.49$ & $9.00 / 0.53$ \\
\hline$P_{\text {nat },} / P_{\text {mod, } \mathrm{kg}}$ & $1.70 / 0.35$ & $2.10 / 0.43$ & $4.50 / 0.92$ & $5.50 / 1.12$ & $7.10 / 1.44$ & $7.80 / 1.58$ & $8.00 / 1.63$ \\
\hline $\mathrm{M}_{\text {nat },}, \mathrm{M}_{\text {mod }, \mathrm{kg}}$ & $1.80 / 0.37$ & $2.20 / 0.46$ & $4.60 / 0.94$ & $5.90 / 1.21$ & $7.40 / 1.51$ & $8.00 / 1.62$ & $8.30 / 1.70$ \\
\hline$D_{\text {nat }, \mathrm{m}} / d_{\text {mod }, \mathrm{m}}$ & $0.40 / 0.020$ & $0.45 / 0.030$ & $0.55 / 0.030$ & $0.60 / 0.035$ & $0.65 / 0.038$ & $0.68 / 0.040$ & $0.73 / 0.043$ \\
\hline$S_{\text {nat }, \mathrm{m}} / S_{\mathrm{mod}, \mathrm{m}}$ & $0.52 / 0.030$ & $0.63 / 0.040$ & $0.75 / 0.045$ & $0.83 / 0.048$ & $0.90 / 0.050$ & $0.95 / 0.060$ & $1.0 / 0.061$ \\
\hline$L_{\mathrm{nat}}, \mathrm{m} / l_{\mathrm{mod}, \mathrm{m}}$ & $1.69 / 0.09$ & $1.90 / 0.11$ & $2.30 / 0.132$ & $2.50 / 0.15$ & $2.70 / 0.16$ & $2.80 / 0.17$ & $3.00 / 0.18$ \\
\hline
\end{tabular}

Under equal values of factors appeared in the stability equation of "Hexablock" (1), its stability parameter $(M)$ is of higher importance in comparison with Dolos and Tetrapod (Fig. 6). 


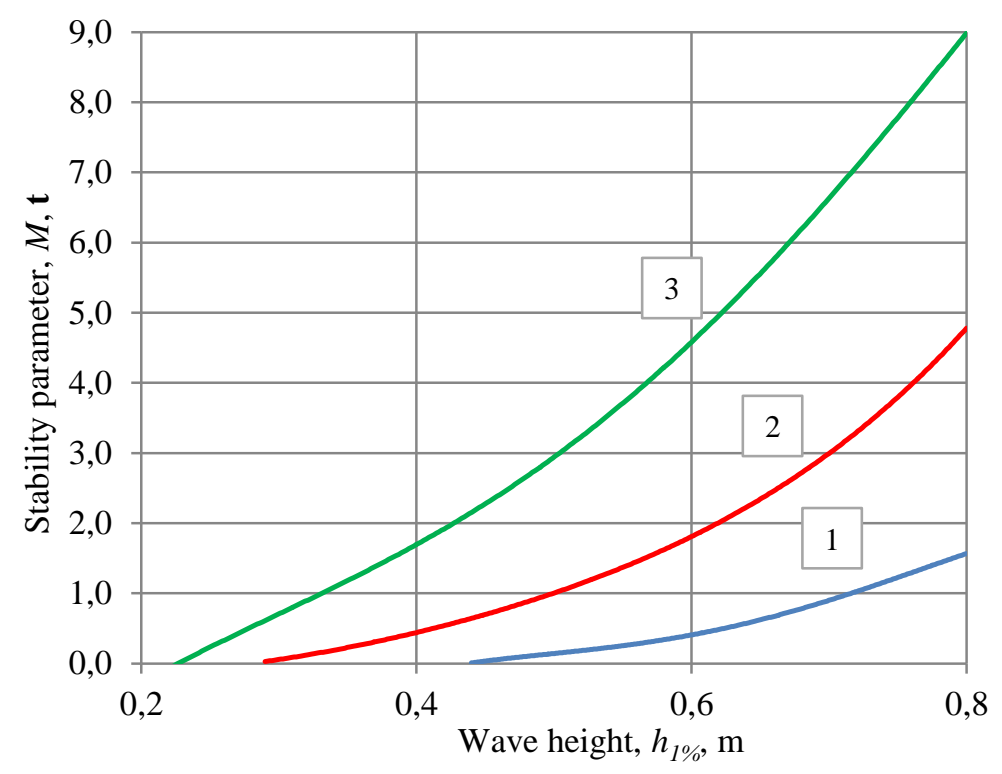

Fig. 6. Dependence of stability parameter $(\mathrm{M})$ on the wave height for different blocks: 1 -"Hexablock" (by formula 1), 2 - Dolos, 3 - Tetrapod

\section{Final results calculation of "hexablock's" wave suppressing effect}

With a view to determine wave suppressing effect of hexablock the height of waves rolled up the smooth slopes was compared with the fill of hexablocks (fig. 4).

Thus, dependence of waves height rolled up on the slope with hexablocks filling is as:

$$
h_{r u \text { u. } u \text {.hex }}=h_{1 \%} \sqrt[3]{\lambda_{1 \%} / h_{1 \%} m^{-1}}
$$

So, the comparison of numerical values of waves height rolled up on the smooth slope and the slope with hexablocks filling has proved considerable wave suppressing property of the latter (Fig. 7).

For the laboratory study of hexablock being under influence of regular waves it is necessary to observe the law of mechanic similarity that assumes presence of geometric, kinematic and dynamic similarities and similar boundary and initial conditions as well.

According to the dimensional analysis [17, 18] the characteristic parameters that determine physics of the process will be:

- parameters describing mechanical system: $L(\mathrm{~m})$ - geometric dimensions, $M$ $\left(\mathrm{kg} \cdot \mathrm{sec}^{2} \cdot \mathrm{m}^{-1}\right)-$ mass, $K\left(\mathrm{~kg} \cdot \mathrm{m}^{-1}\right)-$ factor of rigidity;

- parameters describing the medium: $\rho\left(\mathrm{kg} \cdot \mathrm{sec}^{2} \mathrm{~m}^{-4}\right)-$ mass density; $g\left(\mathrm{~m} \cdot \mathrm{sec}^{-2}\right)-$ acceleration of gravity force; $v\left(\mathrm{~m}^{2} \mathrm{sec}^{-1}\right)$ - kinematic viscosity coefficient; $H_{\mathrm{W}}(\mathrm{m})-$ depth of water;

- parameters describing disturbance: $t(\mathrm{sec})$ - the period of disturbing force, $\delta A(\mathrm{~m})-$ linear amplitudes of constrained oscillations, $v\left(\mathrm{~m} \cdot \mathrm{sec}^{-1}\right)-$ the maximum velocities of liquid particles in troubled water. 


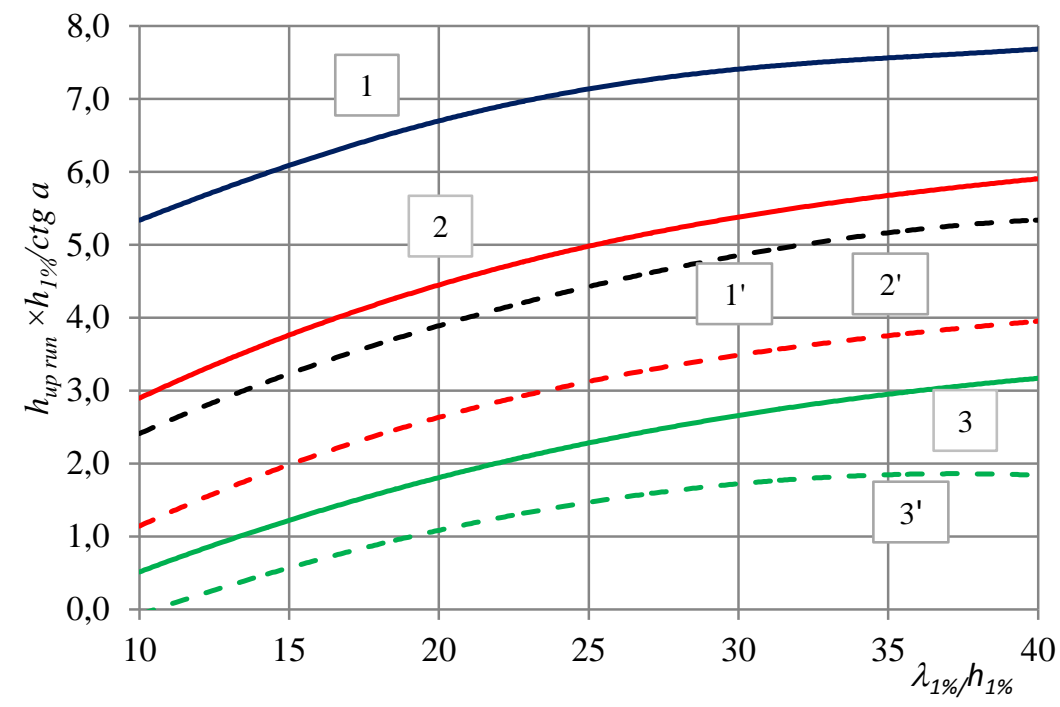

Fig. 7. Dependence of waves run up height on the smooth slope and hexablocks filling on the angle of waves, slope gradient and height of waves:

Smooth slope 1) $\left.\alpha=5^{\circ}(\operatorname{ctg} \alpha=11) ; 2\right)$ Universal curve; 3$) \alpha=30^{\circ}(\operatorname{ctg} \alpha=1.7)$;

$1^{1}, 2^{1}, 3^{1}$ - ditto with hexablocks filling

According to " $\pi$ " theorem the dimensionless quantities sought will depend on dimensionless combinations by:

Froude $F r=\frac{v}{\sqrt{g L}}=i d e m ;$ Reynolds $\operatorname{Re}=\frac{v}{\gamma}=i d e m ;$ Newton $N e=\frac{K}{\rho v^{2} L}=i d e m$;

Struchal $S h=\frac{v t}{L}=i d e m$; Koshi $C h=\frac{m}{\rho L^{3}}=\frac{\rho v^{2}}{E}=i d e m$; Eiler $E_{u}=p / \rho v^{2}=i d e m$,

where $E u\left(\mathrm{~kg} \cdot \mathrm{cm}^{-2}\right)$ is modulus of material elasticity, $\rho\left(\mathrm{kg} / \mathrm{cm}^{-2}\right)$ is the pressure drop.

Among the said six dimensionless criterions the determinant is Froude criterion, which is stipulated by identity of gravitation forces at the model and in nature [6].

Recalculation of hydrodynamic laboratory characteristics to natural up to the zone of waves collapse, when the process runs in auto model zone, is made under consideration of the linear scale of modeling $\left(\alpha_{L}=L_{n a t} / L_{\text {mod }}\right)$. After the zone of waves collapse where auto modeling is not detected)) the height of run up waves and pressure are calculated with the scale correction factor $(K=0.75)$ (tab. 4$)$.

Selection of model and natural parameters of waves depends on their maximum possible values in model or observed in nature. In the small chute $(10.0 \times 0.3 \times 0.7 \mathrm{~m})$ wave parameters were changing $-h=0.05 \div 0.2 \mathrm{~m}, \lambda=0.4 \div 1.2 \mathrm{~m} ;$ In the large chute $(50.0 \times 0.75 \times 1.5 \mathrm{~m})$ wave parameters were changing $h=0.05 \div 0.45 \mathrm{~m}, \lambda=0.4 \div 3.1 \mathrm{~m}$, $t=0.5 \div 7.5 \mathrm{sec}$; In the spatial 3 dimensional basin $(7.0 \times 7.5 \times 1.1 \mathrm{~m})$ wave parameters were changing $-h=0.15 \div 0.35 \mathrm{~m}, \lambda=1.2 \div 3.0 \mathrm{~m}, t=1.8 \div 2.4 \mathrm{sec}$.

According to the maximum values of natural and model wave characteristics the following scales were assumed: for small chute $a_{L}=30^{\circ}$, for large chute $a_{L}=13^{\circ}$ and for the spatial basin $-a_{L}=17^{\circ}$. 
Table 4. Recalculation of natural hydrodynamic characteristics to the lab ones needed under study of hexablock according to Froude criterion ( $\boldsymbol{F} r=\frac{v}{\sqrt{g L}}, q=$ idem, $p=$ idem)

\begin{tabular}{|c|c|c|c|}
\hline Physical quantity & $\begin{array}{c}\text { Scale linear factor } \\
\alpha_{L}=L_{H} / L_{M},(H-\text { natural, } \\
M-\text { model }) \\
\end{array}$ & $\begin{array}{c}\text { Model quantities } \\
\text { before the zone of } \\
\text { waves failure } \\
\end{array}$ & \begin{tabular}{|c|}
$\begin{array}{c}\text { Model quantities in waves run up } \\
\text { and failure zone with allowance } \\
\text { for scale factor } K=0.75\end{array}$ \\
\end{tabular} \\
\hline$h$ (wave height) & $a_{h}=a_{L}=h_{n a t} / h_{\bmod }$ & $h_{\mathrm{mod}}=h_{\text {nat }} / a_{L}$ & $h_{\text {mod }}=h_{\text {nat }} / a_{L}$ \\
\hline$\lambda$ (wave length) & $a_{\lambda}=a_{L}=\lambda_{\text {nat }} / \lambda_{\text {mod }}$ & $\lambda_{\text {mod }}=\lambda_{\text {nat }} / a_{L}$ & $\lambda_{\text {mod }}=\lambda_{\text {nat }} / a_{L}$ \\
\hline$H_{\mathrm{b}}($ water depth) & $a_{b}=a_{L}=H_{n a t, b} / H_{\text {mod }, b}$ & $H_{\text {mod, }, b}=H_{n a t, b} / a_{L}$ & $H_{\text {mod, }, b}=H_{n a t, b} / a_{L}$ \\
\hline $\begin{array}{l}l=3.0 \mathrm{~S}^{*} \\
\text { (hexablock height) }\end{array}$ & $a_{n}=a_{L}=l_{n a t} / l_{\bmod }$ & $l_{\text {mod }}=l_{\text {nat }} / a_{L}$ & $l_{\bmod }=l_{\text {nat }} / a_{L}$ \\
\hline$\Omega$ (area) & $a_{\Omega}=a_{L 3}^{2}$ & $\omega_{\mathrm{mod}}=\omega_{\text {nat }} / a_{L}^{2}$ & $\omega_{\bmod }=\omega_{n a t} / a_{L}^{2}$ \\
\hline$W$ (volume) & $a_{w}=a_{L}^{3}$ & $W_{\bmod }=W_{n a t} / a_{L}^{3}$ & $W_{\bmod }=W_{n a t} / a_{L}^{3}$ \\
\hline $\begin{array}{l}h_{\text {run up }} \text { (wave run up } \\
\text { height) }\end{array}$ & $a_{\text {rumup }}=a_{L}$ & $h_{\text {runup, Nood }}=h_{\text {ramp }, \text {, ant }} / a_{L}$ & $h_{\text {rumup }, \text {, od }}=h_{\text {ruaup }, \text { nat }} / a_{L}$ \\
\hline$t$ (time, period) & $a_{t}=a_{L}{ }^{1 / 2}$ & $t_{\text {mod }}=V_{\text {nat }} / \sqrt{a_{L}}$ & $t_{\text {mod }}=V_{\text {nat }} / \sqrt{a_{L}}$ \\
\hline$\varphi$ (linear velocity) & $a_{V}=a_{L}^{1 / 2}$ & $V_{m o d}=V_{n a t} / \sqrt{a_{L}}$ & $V_{m o d}=V_{n a t} / \sqrt{a_{L}}$ \\
\hline$\alpha$ (angles) & $\alpha_{\alpha}=1$ & $a_{\text {mod }}^{0}=a_{\text {nat }}^{0}$ & $a_{\mathrm{mod}}^{0}=a_{n a t}^{0}$ \\
\hline$M$ (mass) & $a_{M}=a_{L}^{3}$ & $M_{\bmod }=M_{n a t} / a_{L}^{3}$ & $M_{\mathrm{mod}}=M_{n a t} / a_{L}^{3}$ \\
\hline$F$ (force) & $a_{F}=a_{L}^{3}$ & $F_{\bmod }=F_{n a t} / a_{L}^{3}$ & $F_{\bmod }=F_{n a t} / a_{L}^{3}$ \\
\hline$\varepsilon_{\text {por }}$ (porosity) & $a_{\text {nop }}=1$ & $\varepsilon_{\text {por nod }}=\varepsilon_{\text {por nat }}$ & $\varepsilon_{\text {nop nod }}=\varepsilon_{\text {nop nat }}$ \\
\hline$P$ (pressure) & $a_{p}=a_{L}$ & $P_{\bmod }=P_{n a t} / a_{L}$ & $P_{\bmod }=P_{n a t} / a_{L} \cdot K$ \\
\hline
\end{tabular}

* $l=3.0 \cdot S-$ the most efficient dimensions of hexablock from the point of view of wave suppression, block stability on the slope and simplicity of construction (Fig.5).

So, under the maximum height of waves observed at the coastline $h_{\text {nat }}=6.0 \mathrm{~m}$ the maximum model value of waves height in small chute_(dims: $10.0 \times 0.3 \times 0.7 \mathrm{~m}) h_{\bmod 1}=$ $0.2 \mathrm{~m}$ with corresponding scale factor $\alpha_{L 1}=6: 0.2 \approx 30$. In large chute (dims: $50.0 \times 0.75 \times 1.5$ m) $h_{\text {mod } 2}=0.45 \mathrm{~m}$, scale factor $\alpha_{\mathrm{L} 2}=6: 0.45 \approx 13$. In spatial basin (dims: $7.0 \times 7.5 \times 1.1 \mathrm{~m}$ ) $h_{\text {mod } 3}=0.35 \mathrm{~m}$, scale factor $\alpha_{L 3}=6: 0.35 \approx 17$. Then the efficient height of hexablock in small chute $l_{\text {mod } 1}=20: 3 \approx 7 \mathrm{~cm}$, in large chute $l_{\bmod 2}=45: 3 \approx 15 \mathrm{~cm}$, in spatial basin $l_{\text {mod } 3}=$ $35: 3 \approx 12 \mathrm{~cm}$ (According to the world practice it is assumed that the minimum height of hexablock in first approximation equals one third of the wave height). So, to specify the efficient height value of hexablock corresponding model studies must be carried out.

As opposed to open seas where multi-meter difference is observed between high and low tide levels, this difference in the Black Sea region of Georgia is only up to $\Delta \approx 0,5 \mathrm{~m}$ as it is a closed sea (Fig. 8) and a wave height is up to $5 \mathrm{~m}$, (Fig. 9) [19]. Therefore, here figurative blocks can be placed in the most critical zone of waves, i.e. in the depth of 1,5-3,0 $\mathrm{m}$ and as for abrasive banks of water reservoirs, figurative blocks are placed on the areas which are mostly subjected to wash-off, i.e. on the benchmarks of normal pounding or forced levels of reservoirs where the highest waves are observed. 


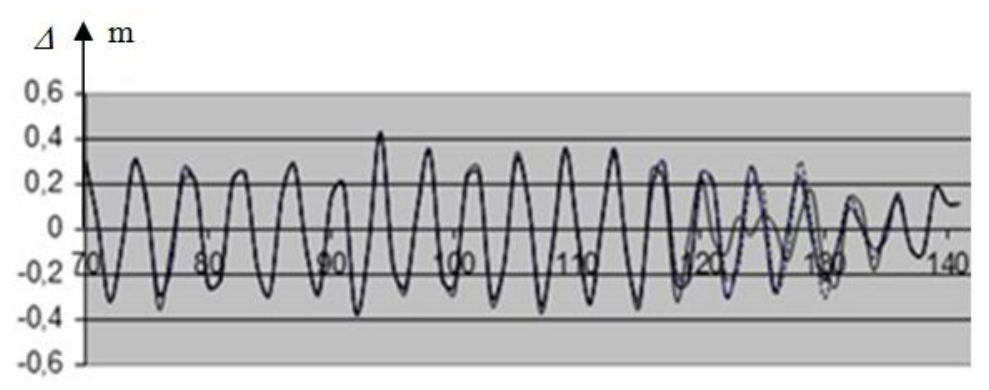

Fig. 8. Variation of level between high and low tides of free surface of the Black Sea near the coast [19]

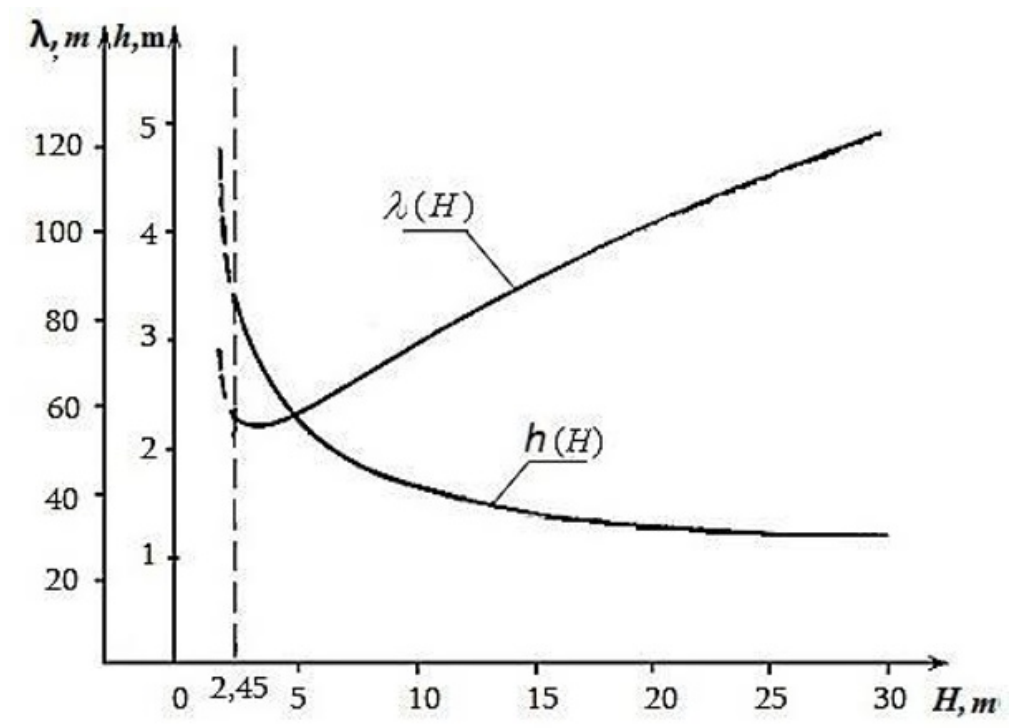

Fig. 9. Curves of variation of wave amplitude and height in the estuary area [19]

\section{Conclusions}

On the basis of study of different shape massives used for protection of washed out banks of sea and reservoirs the procedure of experiments carried out in the hydraulic chutes of various dimensions was worked out at the Institute of Water Management of the Georgian Technical University. The new type of "Hexablock" the efficient wave suppressing reinforced concrete shaped massif that is stable at the slopes is proposed.

The "Hexablock" we created is different from other arrays:

- higher wave breaking effect;

- inter-coupling with widened corners;

- high-through effect of the mound;

- low mass;

- material savings.

Using the universal formula, is calculated the limiting equilibrium on the slope of a "Hexablock" taking into account the minimum allowable weight. 


\section{References}

1. Global Climate Change, NASA, [Online] https://climate.nasa.gov/vital-signs/sea-level/

2. The assessment of the impact of current and future climate change in the Polish zone and the ecosystem of the Baltic Sea. Summary, (Institute of Meteorology and Water Management - National Research Institute, Gdynia 2014)

3. G. Ivavičiūtè, R. Vrubliauskienè, Changes of Baltic Sea Coast During the Period Between 2008 - 2015, Research for Rural Development, V. 1 (2015)

4. Trend in absolute sea level across Europe based on satellite measurements, European Environmental Agency, [Online] https://www.eea.europa.eu/data-andmaps/figures/trend-in-asbolute-sea-level-1

5. S.M. Gorlin, E.I. Mass, M.A. Molina, I.G. Kantarzhi, Experimental determination of drag coefficients for shaped blocks. Tr. CNIS, V. 99 (1976)

6. I.K. Iordanishvili, M.V. Vartanov, K.T. Iordanishvili, I.R. Iremashvili, E.Z. Khosroshvili, Simulation of the process of interaction of waves with the coastal slopes, reinforced riprap and shaped arrays. Water Management Institute of Georgian Technical University, Tbilisi, V. 66 (2011)

7. V.M. Lyather, A.M. Prudovsky, Hydraulic modeling. Energoizdat, Moscow, (1984)

8. I.K. Iordanishvili, K.T. Iordanishvili,. E.Z. Khosroshvili, L.G. Javakhishvili, Study of the effectiveness of the use of shaped arrays on the eroded banks of Adjara. Collected papers of the Georgian Water Management Institute, V. 65, Tbilisi (2010)

9. Sposoby ochrony brzegów morskich i ich wpływ na środowisko przyrodnicze polskiego wybrzeża Battyku. Raport. Red. T. Labuz. (Fundacja WWF. Warszawa 2013)

10. P. Bruun, Design and construction of mounds for breakwaters and coastal protection. (Elsevier Science. Ams. Oxford, N.York,Tokyo 1985)

11. D. Sharpe, Hydraulic modeling, Mir, Moscow (1984)

12. E. Bilyay, B. Özbahçeci, S. Bacanli, G. Kiziroğlu, A New Approach to Breakwater Design - 2B Block, Coastal Engineering Proceedings, Bilyay № 35 (2016)

13. I.I. Na'im, Ab R.M. Shahrizal, M.D. Safari, A Short Review of Submerged Breakwaters, MATEC Web of Conferences 203 (2018)

14. O. Nourani, M.B. Askar, Comparison of the Effect of Tetrapod Block and Armor Xbloc on Reducing Wave Ove Rtopping in Breakwaters. Open Journal of Marine Science, V. 7 (2017)

15. F. Soares, M.J. Henriques, C. Rocha, Concrete Block Tracking in Breakwater Models, Conference: FIG Working Week, Helsinki (2017)

16. L.M. Nogid, The theory of similarity and dimensions. (Sudpromgiz 1967)

17. L.I. Sedov, Methods of similarity and dimension in the mechnics. (Nauka, Moscow 1977)

18. E.V. Kurlovich, Investigation of the stability of coatings from tetrapods. Transport construction, №2 (1958)

19. S. Gagoshidze, M. Kodua, I. Saghinadze, I. Kadaria, River hydro construction and geomorphological processes of the Black Sea coast of Georgia. Monograph, Georgian Technical University, UDC 627.221.2, Tbilisi (2017) 